\title{
News at Biochemia Medica: Research integrity corner, updated Guidelines to authors, revised Author statement form and adopted ICMJE Conflict-of-interest form
}

Ana-Maria Simundic

Editor-in-chief, Biochemia Medica, Zagreb, Croatia

\begin{abstract}
From the issue 23(1) we have implemented several major changes in the editorial policies and procedures. We hope that those changes will raise awareness of our potential authors and reviewers for research and publication integrity issues as well as to improve the quality of our submissions and published articles. Among those changes is the launch of a special journal section called Research Integrity Corner. In this section we aim to publish educational articles dealing with different research and publication misconduct issues. Moreover, we have done a comprehensive revision of our Instructions to authors. Whereas our former Instructions to authors have mostly been concerned with recommendations for manuscript preparation and submission, the revised document additionally describes the editorial procedure for all submitted articles and provides exact journal policies towards research integrity, authorship, copyright and conflict of interest. By putting these Guidelines into action, we hope that our main ethical policies and requirements are now visible and available to all our potential authors. We have also revised the former Authorship and copyright form which is now called the Author statement form. This form now contains statements on the authorship, originality of work, research ethics, patient privacy and confidentiality, and copyright transfer. Finally, Journal has adopted the ICMJE Form for Disclosure of Potential Conflicts of Interest. From this issue, for each submitted article, authors are requested to fill out the "ICMJE Form for Disclosure of Potential Conflicts of Interest" as well as the Author statement form and upload those forms during the online manuscript submission process. We honestly believe that our authors and readers will appreciate such endeavors. In this Editorial article we briefly explain the background and the nature of those recent major editorial changes.
\end{abstract}

Key words: scientific misconduct; plagiarism; editorial policies

\section{Research integrity corner}

In the last issue of Biochemia Medica a newly established position of Research integrity editor was announced. Research integrity editor is a Full member of our Editorial team, whose responsibility is to deal with all matters related to the various aspects of scientific misconduct (1).

With this issue, we launch a Research Integrity Corner, section within our Journal dedicated to all our current and future authors, reviewers and readers. In this journal section, we will publish a series of short educational articles dealing with various research and publication misconduct issues. Editors at Biochemia Medica share a deep respect towards ethical and responsible research (2). We also believe that education is the essence of effective prevention for unethical and questionable practices. Therefore, by launching this educational section we hope to raise awareness of our potential authors and reviewers for research and publication integrity issues and improve the quality of our submissions and published articles.
In this issue, within the Research integrity corner, Supak-Smolcic V and Bilic-Zulle $L$ in their article on Patchwork plagiarism provide a comprehensive overview of patchwork plagiarism or the so-called mosaic writing, its causes and roots as well as effective ways to detect it. It also describes the journal policy towards patchwork plagiarism (3). As nicely described in that article, inexperienced authors whose first language is not English, are most likely to submit "patchwork" article. When writing their articles, such inexperienced authors usually experience some difficulties in finding a proper way to express their thoughts and ideas. This is why they screen available publications for sentences that depict what they originally meant to say and copy such sentences or even whole paragraphs from another article into their own articles as if they were their original work. This is what is considered patchwork plagiarism and such articles shall be rejected for publication. 
To learn more on that topic, all readers are invited to read the entire article.

\section{Updated Guidelines to authors}

In a recent article, which aimed to study the policies and handling procedures for allegations of research and publication misconduct in 399 highly ranked peer-reviewed biomedical journals, it has been shown that only a minor proportion of journals had published their definition of misconduct. It has also been demonstrated that only less than a half of those journals have published policies towards scientific and research misconduct cases and it was concluded that journals and publishers need to standardize their policies and make them available to authors (4).

We have therefore undertaken a comprehensive revision of our Instructions to authors. Whereas our former Instructions to authors have mostly been concerned with recommendations for manuscript preparation and submission, the revised document on top of that also describes the editorial procedure for all submitted articles and provides exact journal policies towards research integrity, authorship, copyright and conflict of interest. By putting these Guidelines into action, we hope that our main ethical statements, policies and requirements are now visible and available to all our future authors.

\section{Author statement form}

To further increase the awareness of authors towards various types of research and publication misconduct and to prevent any potential type of scientific misconduct we have also revised the former Authorship and copyright form which is now called the Author statement form. This form now contains statements on the authorship, originality of work, research ethics (stating whether the procedures in the study were in accordance with the ethical standards of the responsible committee on human experimentation), patient privacy and confidentiality, and copyright transfer. From this issue, for each submitted article, authors are requested to fill out this form and upload it during the online manuscript submission process.

\section{ICMJE Conflict-of-interest form}

To increase the transparency of the published work in our Journal, in 2011, Biochemia Medica has decided to publish a statement on the potential conflict of interest for its every published article (5). To further improve the editorial policy in regards to the issues of conflict of interest, we have now adopted the ICMJE Form for Disclosure of Potential Conflicts of Interest. This form is made available by International Committee of Medical Journal Editors. From this issue, for each submitted article, authors are requested to fill out the "ICMJE Form for Disclosure of Potential Conflicts of Interest" and upload it during the online manuscript submission. The link to the form is accessible from the Guidelines for authors section on the Journal webpage (www.biochemia-medica.com).

\section{Conclusions}

As already previously mentioned, Editors at Biochemia Medica respect and highly appreciate ethical and responsible research. It is our mission to become one of the leading journals in the field of laboratory medicine. The only way to accomplish this goal is by continuously improving the editorial quality. In 2012, we have become the member of COPE (Committee on Publication Ethics), EASE (European Association of Science Editors), CrossRef and CrossCheck and will follow their policies and recommendations.

We hope that such endeavors will be recognized and appreciated by authors and readers.

\section{References:}

1. Simundic AM. Biochemia Medica appoints Research integrity editor. Biochem Med 2012;22:271.

2. Simundic AM. Editing a scientific journal in Croatia: the case of Biochemia Medica. Eur Sci Edit 2012;38:69.

3. Supak Smolcic V, Bilic-Zulle L. Patchwork plagiarism - A jigsaw of stolen puzzle pieces. Biochem Med 2013;23:16-8. http://dx.doi.org/10.11613/BM.2013.004.

4. Bosch X, Hernández C, Pericas JM, Doti P, Marusic A. Misconduct Policies in High-Impact Biomedical Journals. PLoS One. 2012;7:e51928. http://dx.doi.org/10.1371/journal.pone.0051928.

5. Simundic AM. Biochemia Medica introduces the revised policy on Statement of Conflict of Interest. Biochem Med 2011;21:104-5. 